\title{
A hook-effect-free homogeneous light-initiated chemiluminescence assay: is it reliable for screening and the quantification of the hepatitis B surface antigen?
}

\author{
Ruifeng Yang ${ }^{1 \#}$, Liyan Cui ${ }^{2 \#}$, Yan Liu ${ }^{1}, \mathrm{Xu}_{\text {Cong }}{ }^{1}$, Ran Fei ${ }^{1}$, Shuping Wu ${ }^{1}$, Lai Wei ${ }^{1}$ \\ ${ }^{1}$ Peking University People's Hospital, Peking University Hepatology Institute, Beijing Key Laboratory of Hepatitis C and Immunotherapy for Liver \\ Diseases, Beijing International Cooperation Base for Science and Technology on NAFLD Diagnosis, Beijing 100044 , China; ${ }^{2}$ Department of Clinical \\ Laboratory, Peking University Third Hospital, Beijing 100191, China \\ Contributions: (I) Conception and design: R Yang, L Wei; (II) Administrative support: L Wei; (III) Provision of study materials or patients: Y Liu, S \\ Wu; (IV) Collection and assembly of data: R Yang, X Cong, R Fei; (V) Data analysis and interpretation: R Yang; (VI) Manuscript writing: All authors; \\ (VII) Final approval of manuscript: All authors. \\ "These authors contributed equally to this work. \\ Correspondence to: Ruifeng Yang. Peking University People's Hospital, Peking University Hepatology Institute, Key Laboratory of Hepatitis C and \\ Immunotherapy for Liver Diseases, Beijing International Cooperation Base for Science and Technology on NAFLD Diagnosis, Beijing 100044, \\ China. Email: yangruifeng@pkuph.edu.cn; yangruifeng103@163.com.
}

Background: Hepatitis B virus (HBV) infection remains a threat to global public health. As a hallmark of $\mathrm{HBV}$ infection, hepatitis B surface antigen (HBsAg) has been used to screen for HBV infection for decades, and quantitative assays are also being clinically rejuvenated to predict the disease outcome and monitor the antiviral response. Herein, we developed and evaluated a hook-effect-free homogeneous quantitative $\mathrm{HBsAg}$ assay based on the light-initiated chemiluminescence immunoassay (LICA).

Methods: A hook-effect-free LICA algorithm was established by measuring the relative light units (RLUs) of two time points during the immunoreaction. The precision was assessed using low- and high-level controls. Consecutive clinical serum samples were tested using the LICA and Abbott Architect assay; samples producing inconsistent results were retested using supplementary assays including the HBsAg neutralization, HBV DNA, and Roche Elecsys HBsAg assays for further confirmation. The consistency, sensitivity, specificity, and positive and negative predictive values (PPV and NPV) were calculated. For the quantitative results, the correlation was analyzed. The coverage of different genotypes and mutations by the LICA was evaluated. Moreover, serial on-treatment and follow-up samples from chronic hepatitis B patients were also measured using the two assays.

Results: The LICA had better within-run and within-laboratory precisions than the Architect assay. In total, 5,176 clinical samples were tested. The two assays showed a consistency of $99.63 \%$. The LICA showed greater specificity (99.95\% vs. 99.77\%) and PPV (99.75\% vs. 98.77\%) than the Architect assay, whereas the Architect assay showed greater sensitivity (100.00\% vs. $99.01 \%)$ and NPV (100.00\% vs. 99.82\%). The two assays displayed an excellent correlation independent of genotypes and mutations. The LICA hookfree algorithm recognized $100 \%$ of the underestimated results. Furthermore, similar HBsAg dynamics were demonstrated using the LICA and Architect HBsAg assay.

Conclusions: The hook-free LICA provides a reliable tool for screening for HBV infection and quantifying HBsAg.

Keywords: Hepatitis B virus (HBV); hepatitis B surface antigen (HBsAg); light initiated chemiluminescence immunoassay (LICA); hook-effect-free technology

Submitted Nov 04, 2019. Accepted for publication Jan 30, 2020.

doi: $10.21037 /$ atm.2020.02.59

View this article at: http://dx.doi.org/10.21037/atm.2020.02.59 


\section{Introduction}

Hepatitis $B$ virus (HBV) infection remains a major issue regarding global public health (1). Increased attention should be paid to the countries of the Asia-Pacific region where $\mathrm{HBV}$ infection is endemic (2). For instance, the prevalence of hepatitis B surface antigen (HBsAg) is greater than $7 \%$ in China; accordingly, there are approximately 93 million viral carriers, among whom 30 million are chronic hepatitis $\mathrm{B}(\mathrm{CHB})$ patients in need of antiviral treatment $(3,4)$. CHB patients are far more likely to progress to liver cirrhosis and hepatocellular carcinoma (HCC) (5).

HBsAg is a hallmark of $\mathrm{HBV}$ infection, and the HBsAg assay has been used to screen for $\mathrm{HBV}$ infection for decades (6). A sensitive HBsAg assay helps diagnose the occult $\mathrm{HBV}$ infection (OBI) and prevent hepatitis caused by viral reactivation in 12 out of $13 \mathrm{HBV}$-resolved patients undergoing systemic chemotherapy (7). Meanwhile, the use of quantitative HBsAg assays has also been clinically rejuvenated recently. Serum HBsAg level is associated with the activity of the covalently closed circular deoxyribonucleic acid (cccDNA) in liver cells, and a low level of $\mathrm{HBsAg}$ predicts a low risk of HCC (8). HBsAg quantification helps identify different phases of natural course of chronic infection (9). For instance, HBsAg $<1,000$ international unit $(\mathrm{IU}) / \mathrm{mL}$ in combination with $\mathrm{HBV}$ DNA $<2,000 \mathrm{IU} / \mathrm{mL}$ can accurately differentiate inactive $\mathrm{HBV}$ carriers from those with e antigen (HBeAg)negative hepatitis $\mathrm{B}$ (10). For CHB patients treated with peginterferon, on-treatment $\mathrm{HBsAg}$ monitoring helps predict $\mathrm{HBeAg}$ loss or seroconversion. For instance, we previously showed that serum $\mathrm{HBsAg} \geq 1,500 \mathrm{IU} / \mathrm{mL}$ at week 12 and $\geq 2,890 \mathrm{IU} / \mathrm{mL}$ at 24 weeks of treatment has a high negative predictive value (NPV; 91\% and 95\%, respectively) for $\mathrm{HBeAg}$ seroconversion 24 weeks after treatment (11). The absence of an HBsAg decline at 12 weeks of interferon treatment can identify nonresponders and determine the early discontinuation of therapy (12). In contrast, it is more difficult to achieve significant $\mathrm{HBsAg}$ decline with nucleos(t)ide analogue (NA) treatment regimens. Consequently, a fast decline in $\mathrm{HBsAg}$ at 24 weeks of treatment usually has a high positive predictive value (PPV) for the clearance of HBsAg (13). Moreover, HBsAg $<100 \mathrm{IU} / \mathrm{mL}$ is a good predictor for NA treatment cessation with a low risk of virological and clinical relapse
$(13,14)$, and a serial HBsAg quantitative assays can also be used for the re-treatment decision in NA-experienced $\mathrm{CHB}$ patients with hepatitis flare (15). In recent years, novel direct acting antivirals (DAAs) and immune modulators aiming at "functional cure" are under development $(16,17)$. Functional cure is defined as durable HBsAg loss $(<0.05 \mathrm{IU} / \mathrm{mL})$ as well as undetectable serum HBV DNA after completing a course of treatment (18). It has been regarded as the primary endpoint for present and future therapeutic strategies. HBsAg loss in $\geq 30 \%$ of patients is an acceptable response rate for clinical trials, and it should be preceded by a decline in HBsAg level. Therefore, the HBsAg quantitative assay is essential, and the analytical sensitivity, accuracy, and linear range still need to be improved accordingly.

HBsAg immunoassays are classified into two categories: the one-step and two-step assays. The one-step assay completes the reaction in a homogeneous system without a washing stage, providing results more rapidly $(7,19,20)$. However, it suffers from the hook effect, because excess antigens bind to the capture and detection antibodies, preventing the immunoreaction and resulting in an underestimated or even a false negative result. Currently, the mainstream immunoassays for detecting HBsAg are chemiluminescent immunoassays (CLIAs), including the chemiluminescent microparticle immunoassay (CLMIA), the electrochemiluminescence immunoassay (ECLIA), and the chemiluminescent enzyme immunoassay (CLEIA) (19-24). Recently, a novel HBsAg quantitative assay based on a distinctive technology, i.e., light-initiated chemiluminescence immunoassay (LICA) technology, has been developed. As a modified version of the luminescent oxygen channeling immunoassay (25), the LICA is performed in a homogeneous reaction system and washing steps are not needed. Moreover, the diameter of the microbeads is only $1 / 5$ that of the magnetic beads used in CLMIA assays, forming a stable reagent suspension. Therefore, reagent mixing prior to the initiation of the test is not needed. In addition, an increased total surface area is provided for the immunoreaction. Theoretically, the LICA has the potential to provide a simple, fast, and more precise and cost-effective way of detecting HBsAg. Furthermore, we developed an algorithm that resolves the hook effect. In this study, we evaluated the performance and usefulness of the hook-free homogeneous LICA for screening and 
quantifying HBsAg.

\section{Methods}

\section{The HBsAg assays}

The LICA HBsAg quantitative assay and the hook-free principle

The principle of the LICA is different from that of the CLMIA (Figure $1 A$ vs. 1B). Two types of biotinylated anti-HBs monoclonal antibodies (mAbs) are used to coat the sensitizer beads. Polyclonal anti-HBs antibodies are crosslinked onto the emission beads. The distance between the sensitizer and emission beads decreases in the presence of HBsAg. In response to a $680-\mathrm{nm}$ laser, the sensitizer bead releases singlet oxygen $\left({ }^{1} \mathrm{O}_{2}\right)$ molecules and catalyzes the methylthiophene derivatives on the emission beads to release ultraviolet light. Under ultraviolet light, the europium $(\mathrm{Eu})$ on the emission beads glows, and the relative light units (RLUs) correlate with the HBsAg concentration. The assay was automatically performed on a LICA 800 immunoanalyzer.

The assay had an analytical measurement range (AMR) of $0.20-500.00 \mathrm{ng} / \mathrm{mL}$ and a lower limit of detection (LOD) of $0.20 \mathrm{ng} / \mathrm{mL}$. The AMR and LOD were calculated using serially diluted HBsAg standards from the National Institutes for Food and Drug Control, which are used as the national reference material in China. The coefficient of variation (CV) at the levels of 0.20 and $500.00 \mathrm{ng} / \mathrm{mL}$ was less than $15 \%$.

The hook-free technology is based on a patented algorithm. Theoretically, Eu light induces the dissociation of HBsAg-anti-HBs complexes, resulting in a rebound of the signal (Figure 1C). The long-term glow allows for the measurement of the RLUs at two time points. A significantly increased RLU indicates the existence of the hook effect. The potentially hooked results are recognized and flagged by the hook-free algorithm embedded in the LICA 800 application software. In the setting where a quantitative HBsAg result is needed, a subsequent 1:1,000 onboard dilution should be performed. Serially diluted serum samples with HBsAg results quantified by the Architect assay were used to determine the optimal value of the two-point RLU ratio, which was used to recognize the potential hooked results. The highest HBsAg concentration was approximately $100,000 \mathrm{IU} / \mathrm{mL}$.

\section{The Architect HBsAg assay}

The Architect CLMIA (Abbott, Sligo, Ireland) had an AMR of $0.05-250 \mathrm{IU} / \mathrm{mL}$ and an LOD of $0.05 \mathrm{IU} / \mathrm{mL}$. Other features were detailed in our previous study (21). The assay was performed on an Architect i2000 ${ }_{\mathrm{SR}}$ immunoanalyzer, and a result greater than $250 \mathrm{IU} / \mathrm{mL}$ automatically triggered a 1:500 onboard dilution until the final concentration was obtained.

\section{Interpretation of the LICA and Architect HBsAg results}

According to the manufacturer's instructions, all initially positive samples were retested in duplicate following a $10,000 \times \mathrm{g}$ and $10 \mathrm{~min}$ centrifugation. If both retest results were nonreactive, the sample was considered nonreactive; if either was reactive, the sample was considered positive for HBsAg.

The Architect HBsAg qualitative II confirmatory assay The existence of HBsAg was confirmed by means of specific antibody neutralization. The results of the Architect HBsAg qualitative II confirmatory assay (Abbott, Sligo, Ireland) were based on the sample/cutoff ratio (S/Co) and $\%$ neutralization of the sample. A sample was considered positive if the non-neutralized sample result was greater than or equal to $0.70 \mathrm{~S} / \mathrm{Co}$, and the RLU of the neutralized sample compared to the non-neutralized sample was reduced by at least $50 \%$. Otherwise, it was interpreted as indeterminate.

\section{The Elecsys HBsAg II qualitative assay}

The Elecsys ECLIA (Roche, IN, USA) was used as a reflex test for the discrepant or indeterminate HBsAg results. The assay was performed on a Molecular E170 immunoanalyzer. A result greater than or equal to the 0.90 cutoff index (COI) was considered positive. An initially positive sample was retested. If the retest result was nonreactive, the sample was considered negative; if the retest value was reactive, it was considered positive for HBsAg.

\section{HBV DNA assay, genotyping assay and HBsAg mutant analysis within the " $a$ " determinant region}

The viral load was measured using the TaqMan HBV 2.0 assay with an LOD of $20 \mathrm{IU} / \mathrm{mL}$ (Roche, NJ, USA). The genotype was determined through the phylogenetic analysis of the $\mathrm{S}$ gene. Furthermore, the amino acid sequence of the "a" determinant region (from positions 124 to 147) was analyzed using BioEdit 7.0 (Ibis Biosciences, CA, USA). The DNA extraction, nested polymerase chain reaction 


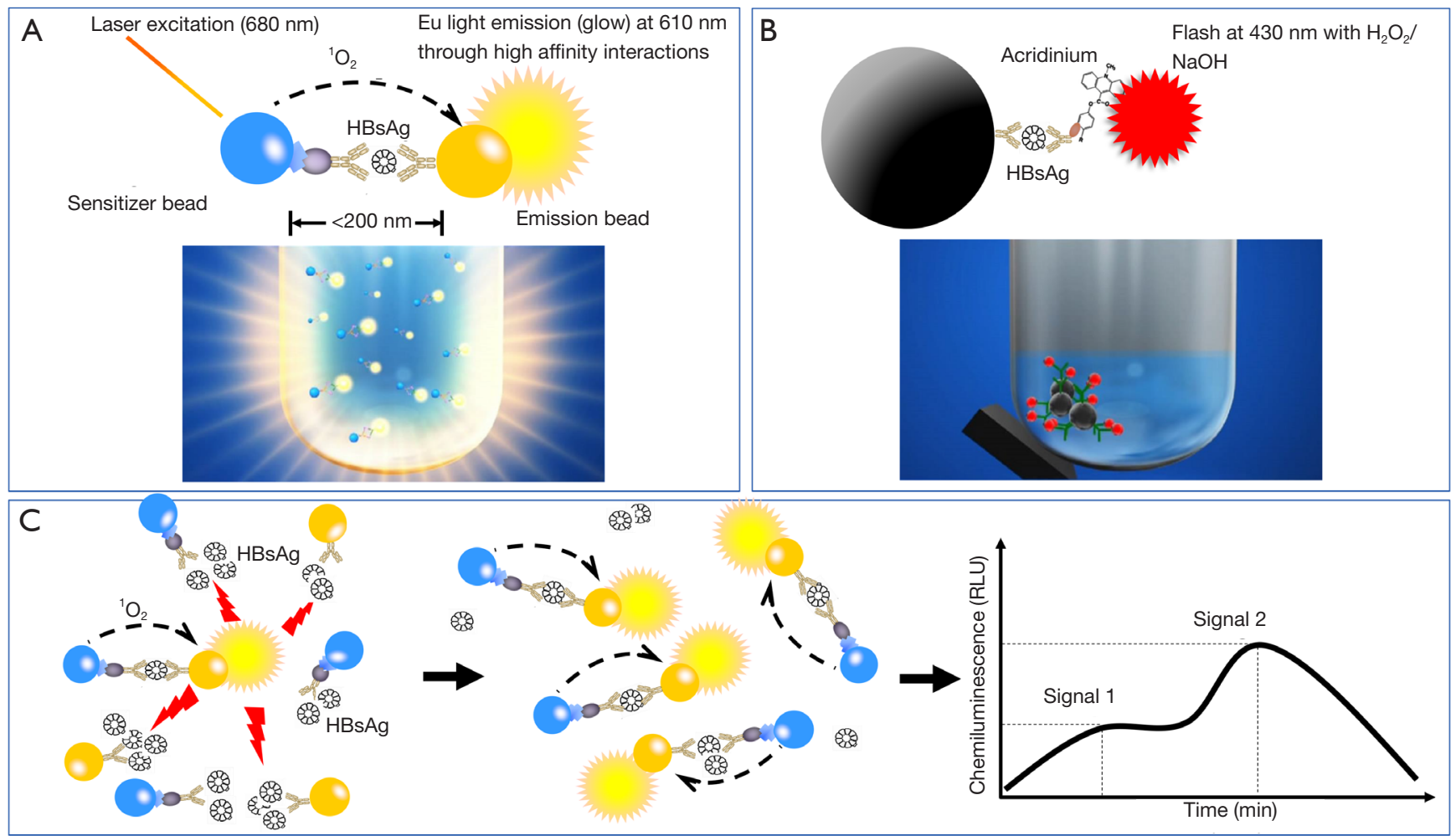

Figure 1 Principle comparison of the LICA HBsAg assay (A) and the Architect HBsAg assay (B), and the schematic illustration for the LICA hook-free principle (C). ${ }^{1} \mathrm{O}_{2}$, singlet oxygen; Eu, europium; HBsAg, hepatitis B surface antigen; RLU, relative light unit.

(PCR), and population and clonal sequencing procedures are described in our previous studies $(21,26)$.

\section{Controls and precision assessment}

Two sets of positive controls were established by pooling HBsAg-positive sera and diluting them with negative sera. The concentration of the low-positive control was adjusted to approximately 2 -fold the LOD of the assays. The highpositive control was adjusted to approximately $100 \mathrm{IU} / \mathrm{mL}$, which is used as a benchmark for low-level HBsAg and NA treatment cessation $(13,14)$. Within-run and withinlaboratory precision was calculated and expressed as $\mathrm{CV}$ $(19,21)$.

\section{Clinical samples and the testing sequence}

From July to October 2018, consecutive routine serum samples were collected and tested using the Architect and LICA assays in parallel. The samples were kept at $-20{ }^{\circ} \mathrm{C}$ until further analysis. For samples with inconsistent qualitative results, supplementary assays were performed to confirm the existence of HBsAg. The testing sequence is shown in Figure 2.

\section{Serial serum samples from $\mathrm{CHB}$ patients treated with peginterferon and then followed up}

Serial samples from four patients were available for HBsAg measurement using the LICA and Architect assays. The patients were treated with peginterferon for 6 months and then followed up for 9 years. The clinical information is detailed in our previous study, and the dynamics of other biomarkers, including HBeAg and HBV DNA, are available (27).

\section{Statistical analysis}

Statistical analyses were performed using GraphPad Prism 6 (GraphPad, CA, USA) and SPSS 22 (IBM, New York, USA). For qualitative results produced by the LICA and Architect assay, the sensitivity, specificity, accuracy, PPV, 


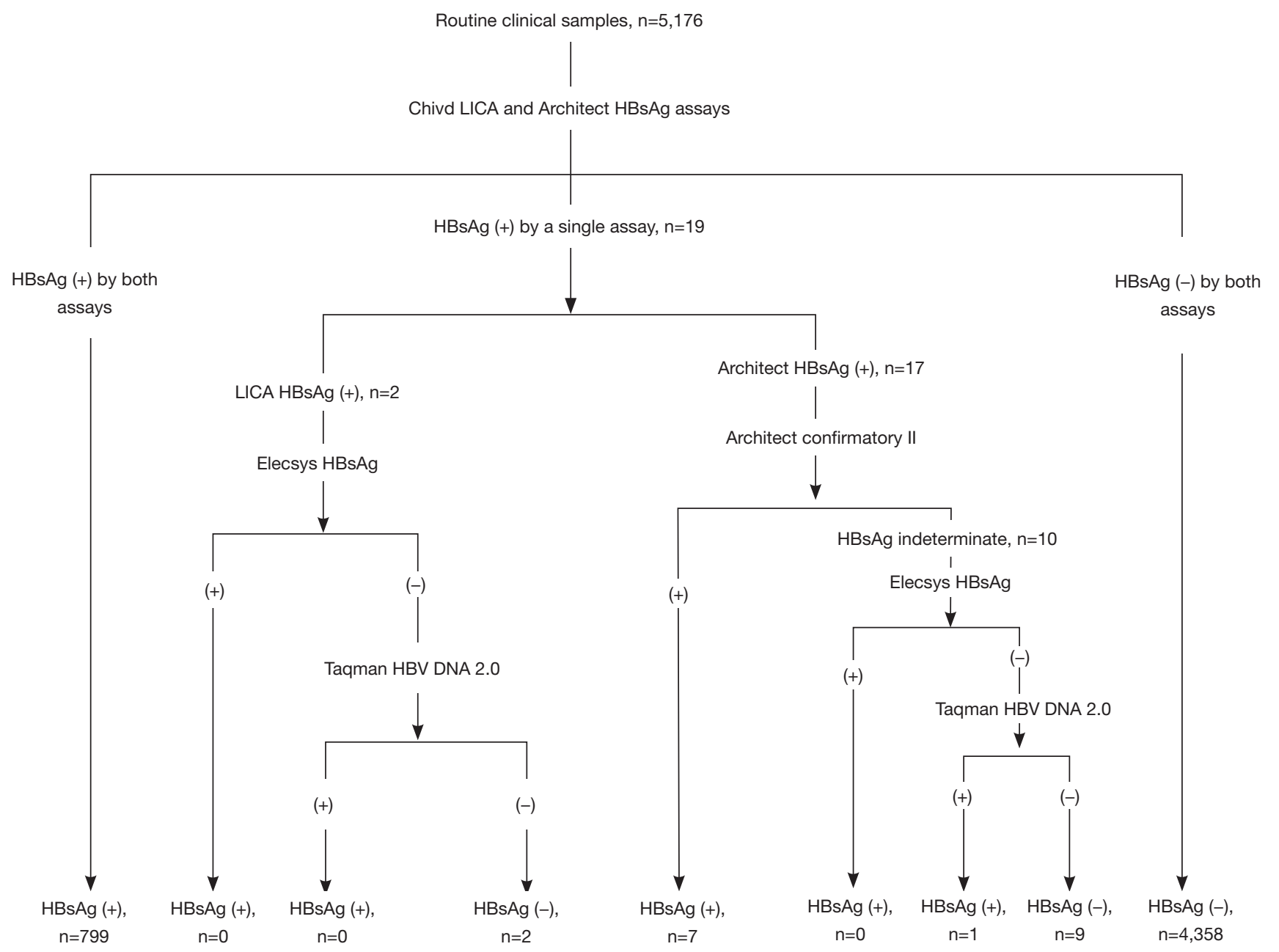

Figure 2 Testing sequencing and HBsAg results for routine clinical samples $(n=5,176)$. LICA, light-initiated chemiluminescence immunoassay; HBsAg, hepatitis B surface antigen; HBV, hepatitis B virus.

NPV and 95\% confidence intervals (CIs) were calculated. Kappa values were used to assess consistency $(>0.75$ indicating high consistency and $<0.40$ indicating poor consistency). For quantitative results, correlations were analyzed using Pearson's correlation coefficient. Slopes and intercepts were also compared to identify if the regression lines were different. Statistical significance was defined as $\mathrm{P}<0.05$.

\section{Results}

\section{Establishment and evaluation of the book-free function}

The hook-free algorithm was based on the determination of the RLUs 12 and 15 minutes after the immunoreaction was initiated. The 3-minute interval yielded the best distinguishability (Figure 3). HBsAg results above the level of approximately $10^{4} \mathrm{IU} / \mathrm{mL}$ might be hooked. Interestingly, the results with an $\mathrm{RLU}_{15 \text { min }} / \mathrm{RLU}_{12 \text { min }}$ ratio $>2.0$ could be very clearly identified as hook-effect results. They were automatically flagged by the LICA 800 machine, and the corresponding samples were subjected to onboard dilution and retesting.

\section{Precision of the LICA and Architect HBsAg assays}

Within-run and within-laboratory precision values are 


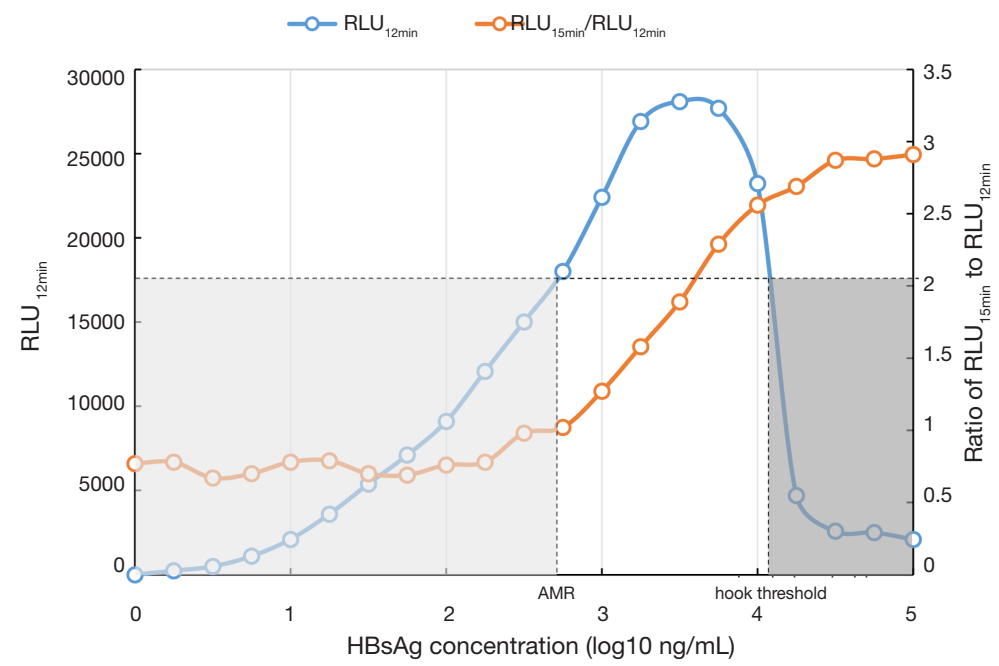

Figure 3 Elimination of the hook effect by monitoring the ratio of two-point RLUs produced during the reaction. The light-gray zone represents the results within the analytical range of the LICA, and the dark-gray zone indicates those also falling into the analytical range but being drastically underestimated due to the hook effect. After the $\mathrm{RLU}_{15 \mathrm{~min}} / \mathrm{RLU}_{12 \mathrm{~min}}$ ratio was assessed, the results with a ratio $>2.0$ were distinguished and automatically subjected to onboard dilution and retesting. AMR, analytical measurement range; RLU, relative light unit.

Table 1 Precision of the LICA and Architect HBsAg assays

\begin{tabular}{lccc}
\hline Assay (unit) & Target value of the controls & Within-run precision CV (\%) & Within-laboratory precision CV (\%) \\
\hline LICA $(\mathrm{ng} / \mathrm{mL})$ & 0.44 & 2.43 & 4.62 \\
& 399.22 & 2.07 & 4.61 \\
Architect $(\mathrm{IU} / \mathrm{mL})$ & 0.11 & 6.98 & 9.93 \\
& 106.02 & 4.90 & 7.84 \\
\hline
\end{tabular}

$\mathrm{CV}$, coefficient of variation; LICA, light initiated chemiluminescence immunoassay.

shown in Table 1.

\section{Performance characteristics of the LICA and the Architect HBs Ag assay in the qualitative analysis}

A total of 5,176 samples were included in the comparison, among which 799 samples gave double-positive HBsAg results in the two assays, and 4,358 samples gave doublenegative results. The consistency between the two assays was $99.63 \%$ (95\% CI, 99.47-99.80\%) with a kappa value of 0.99 (95\% CI, 0.98-0.99). The remaining 19 samples tested positive in a single assay were subsequently subjected to further testing. The final results are shown in Figure 2. The performance characteristics are listed in Table 2. Eight HBsAg-positive samples were missed by the LICA, and their information is provided in Table 3. Eleven
HBsAg-negative samples were tested positive using either assay (Table 4). The positive rate of HBsAg in the study population was $15.59 \%(807 / 5,176)$, which is higher than that of the general Chinese population (3).

\section{Correlation of the double-positive quantitative results that fell into the analytical range of the LICA, and the distinguishability of the high-level-HBs Ag samples by the book-free function}

There were 188 double-positive quantitative results that fell into the AMR of the LICA. The results of 46 samples with high-level HBsAg (>10,000 IU/mL, measured by the Architect assay) were underestimated when we intentionally disabled the hook-free function (Figure 4A). However, when the hook-free function was enabled, all of the high-level 
Table 2 Performance characteristics of the LICA and the Architect HBsAg assay $(\mathrm{n}=5,176)$

\begin{tabular}{lcc}
\hline Variables & LICA & Architect \\
\hline Sensitivity $(95 \% \mathrm{Cl})(\%)$ & $99.01(98.06-99.57)$ & $100.00(99.54-100.00)$ \\
Specificity $(95 \% \mathrm{Cl})(\%)$ & $99.95(99.83-99.99)$ & $99.77(99.58-99.89)$ \\
Accuracy $(95 \% \mathrm{Cl})(\%)$ & $99.81(99.69-99.93)$ & $99.83(99.71-99.94)$ \\
PPV $(95 \% \mathrm{Cl})(\%)$ & $99.75(99.10-99.97)$ & $98.77(97.76-99.41)$ \\
NPV (95\% Cl) (\%) & $99.82(99.64-99.92)$ & $100.00(99.92-100.00)$ \\
\hline
\end{tabular}

LICA, light initiated chemiluminescence immunoassay; HBsAg, hepatitis B surface antigen; Cl, confidence interval; PPV, positive predictive value; NPV, negative predictive value.

samples were flagged as "potentially hooked", and a 1:1,000 onboard dilution was triggered. The final concentrations correlated well with these 46 results (Figure $4 B$ ). There were no significant differences in the slope and intercept of the two lines $(\mathrm{P}=0.60$ for the slope and $\mathrm{P}=0.69$ for the intercept). The equation for all 188 samples was $y=1.11 x$ $+0.51\left(\mathrm{R}^{2}=0.97, \mathrm{P}<0.001\right)$.

\section{Comparison of the two assays for the quantification of HBs Ag in samples with different HBV genotypes and mutations}

The abovementioned 188 samples were excluded for genotyping and mutation testing. The remaining 201 HBeAg-positive samples were tested using the TaqMan HBV 2.0 assay. There were 107 viremic samples, among which 102 samples with viral loads greater than 200 IU/ $\mathrm{mL}$ were genotyped successfully. Thirty-six samples were determined as genotype $\mathrm{B}, 65$ were $\mathrm{C}$ and the remaining sample was D. Moreover, 10 (9.80\%) samples harbored mutation(s) in the "a" determinant region, including T126A [1], Q129H [1], Q129R [1], M133L [1], T143L [1], T140S [1], G145R [1], G145E [1], T126N+P127T+G145A [1], and T126S+T131N+M133T+G145A [1], as shown in Figure $4 C$. The proportion of the mutant quasispecies ranged from $57.14 \%$ to $96.67 \%$, as confirmed by clonal sequencing.

HBsAg results quantified using the LICA and the Architect assay correlated very well (Figure 4C,D). Furthermore, the lines from subgroups with genotypes B and $\mathrm{C}$ were not significantly different $(\mathrm{P}=0.59$ for the slope and $\mathrm{P}=0.45$ for the intercept). The lines from subgroups with and without mutation(s) were not significantly different ( $\mathrm{P}=0.90$ for the slope and $\mathrm{P}=0.59$ for the intercept). Overall, the regression line (Figure $4 C, D$ ) was not significantly different from that shown in Figure $4 B(\mathrm{P}=0.08$ for the slope and $\mathrm{P}=0.25$ for the intercept). Consequently, the pooled regression line consisting of all 290 results was $y=1.10 x$ $+0.52\left(\mathrm{R}^{2}=0.97, \mathrm{P}<0.001\right)$.

\section{HBs Ag dynamics in CHB patients treated with peginterferon and followed up for 9 years}

Serial serum samples from four CHB patients treated with interferon and then followed up were available for HBsAg quantification using the LICA. The dynamics of the biomarkers are shown in Figure 5.

\section{Discussion}

Both the Architect and LICA HBsAg assays can be used as a screening tool. The comparison of the qualitative results generated by the two assays showed that each assay had its merits and disadvantages. Although the two assays showed very high consistency (99.63\% with a kappa value of 0.99$)$, the LICA showed a better clinical specificity and PPV than the Architect assay. In contrast, the LICA was slightly less sensitive than the Architect assay for the clinical diagnosis of HBV infection. We explored the characteristics of the 8 missed samples. Seven samples were from infectors with undetectable DNA, and most had a normal alanine aminotransferase (ALT) result, indicating that they were in an inactive carrier phase $(10,28)$. The remaining sample was from a patient undergoing stem cell transplantation and immunosuppression. The serum HBsAg level was very low $(0.06 \mathrm{IU} / \mathrm{mL})$ and serum HBV DNA could be detected. The patient had a positive anti-HBc and anti-HBe result, indicating a previous $\mathrm{HBV}$ infection and presence of cccDNA in the liver cell nucleus. For such patients with a severely impaired immune response, $\mathrm{HBV}$ reactivation is very likely, and frequent HBV DNA monitoring is necessary 
Table 3 Characteristics of the HBsAg-positive samples missed by the LICA ( $\mathrm{n}=8)$

\begin{tabular}{|c|c|c|c|c|c|c|c|c|c|c|c|c|}
\hline$\#$ & Diagnosis & Age & Gender & $\begin{array}{l}\mathrm{HBsAg}(\mathrm{ng} / \mathrm{mL} \\
\text { LICA) }\end{array}$ & $\begin{array}{l}\mathrm{HBsAg}(\mathrm{IU} / \mathrm{mL} \text {, } \\
\text { Architect) }\end{array}$ & Anti-HBs & $\mathrm{HBeAg}$ & $\begin{array}{l}\text { Anti- } \\
\mathrm{HBe}\end{array}$ & $\begin{array}{l}\text { Anti- } \\
\text { HBc }\end{array}$ & $\begin{array}{l}\text { Anti-HBc } \\
\lg M\end{array}$ & $\begin{array}{c}\text { HBV DNA } \\
(\mathrm{IU} / \mathrm{mL})\end{array}$ & $\mathrm{ALT}(\mathrm{U} / \mathrm{L})$ \\
\hline 1 & $\begin{array}{c}\text { Stem cell } \\
\text { transplantation } \\
\text { for the Burkitt's } \\
\text { lymphoma }\end{array}$ & 22 & Male & $0.08,-$ & $0.06,+$ & - & - & + & + & - & 140 & 96 \\
\hline 4 & Prosopospasm & 53 & Female & $0.05,-$ & $0.14,+$ & + & - & - & + & - & - & 40 \\
\hline 5 & $\begin{array}{l}\text { Implantation of } \\
\text { pacemaker }\end{array}$ & 85 & Male & $0.05,-$ & $0.10,+$ & - & - & + & + & - & - & 8 \\
\hline 6 & HBsAg positive & 66 & Female & $0.12,-$ & $0.27,+$ & - & - & + & + & - & - & 15 \\
\hline 8 & $\begin{array}{l}\text { Myelodysplastic } \\
\text { syndrome }\end{array}$ & 73 & Female & $0.08,-$ & $0.22,+$ & - & - & + & + & - & - & 38 \\
\hline
\end{tabular}

LICA, light-initiated chemiluminescence immunoassay; IU, international unit; HBsAg, hepatitis B surface antigen; HBeAg, hepatitis B e antigen; HBc, hepatitis B core antigen; ALT, alanine aminotransferase; DNA, deoxyribonucleic acid; -, negative; +, positive; NA, not available; $\mathrm{CHB}$, chronic hepatitis $\mathrm{B}$.

Table 4 Characteristics of the HBsAg-negative samples that gave a false positive result in either assay (n=11)

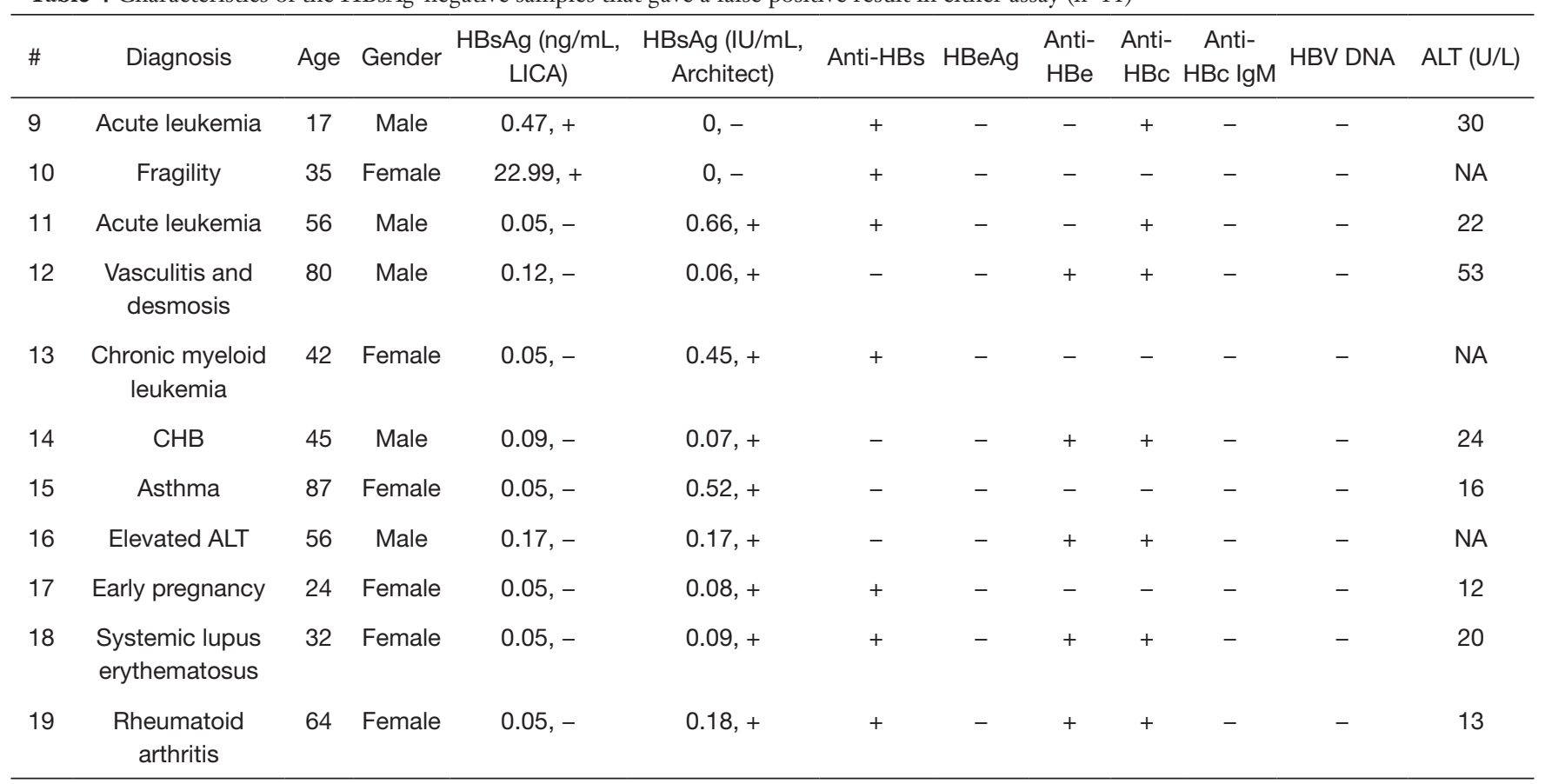

-, negative; +, positive; HBsAg, hepatitis B surface antigen; LICA, light-initiated chemiluminescence immunoassay; IU, international unit; $\mathrm{HBeAg}$, hepatitis B e antigen; HBV, hepatitis B virus; ALT, alanine aminotransferase; $\mathrm{CHB}$, chronic hepatitis B. 

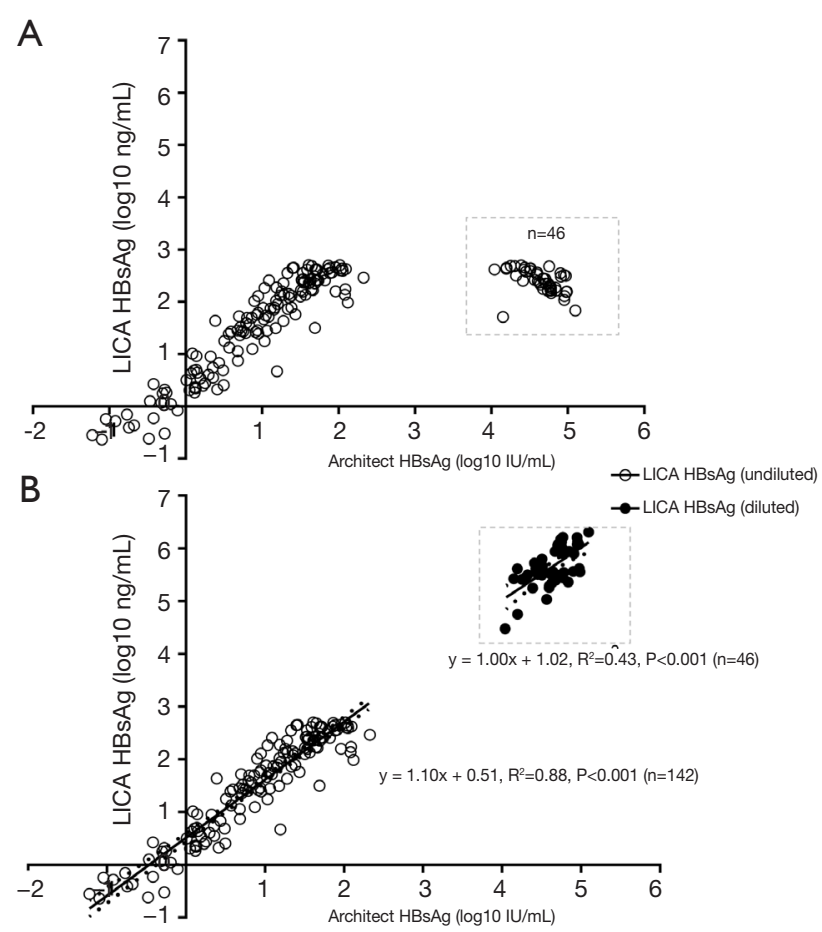
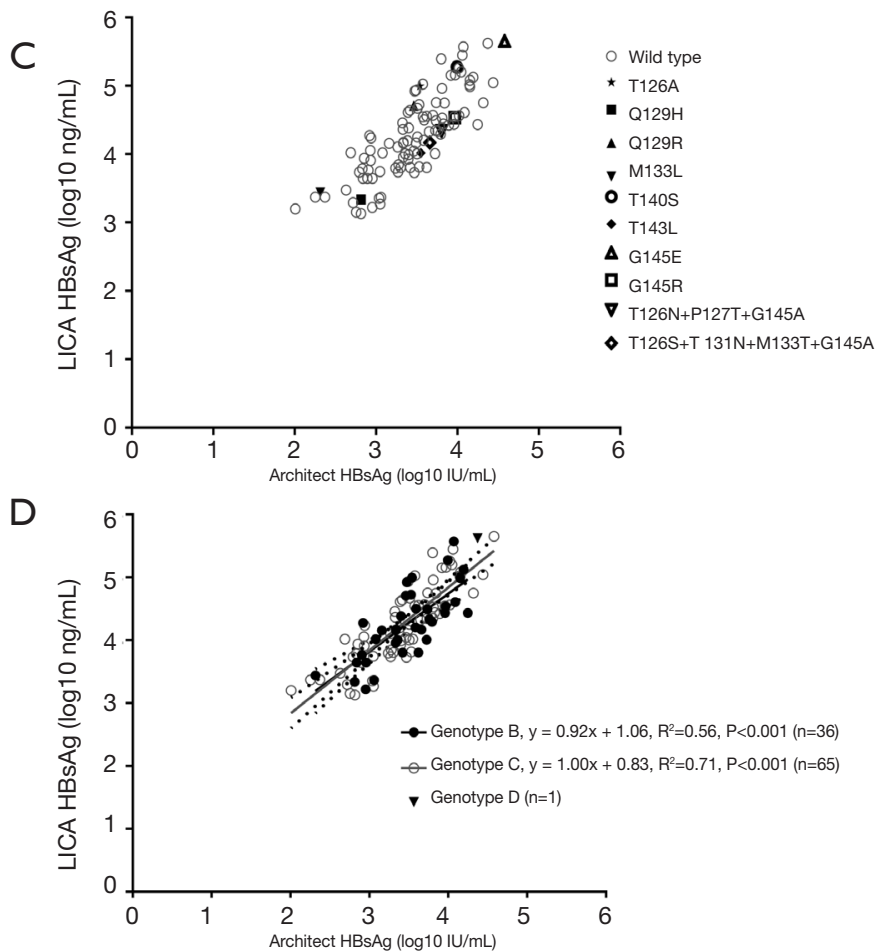

Figure 4 Correlations of the HBsAg results measured using the LICA and the Architect assay. Forty-six hooked results were observed in the dotted box in the absence of the hook-free technology (A). These results were recognized by the hook-free technology, and the final hook-free results correlated well with the Architect results (B). Correlations in samples with genotypes B, C or D and in samples with or without HBsAg mutants are also shown (C,D). The dashed lines indicate the $95 \%$ CI of the linear regression. LICA, light-initiated chemiluminescence immunoassay; HBsAg, hepatitis B surface antigen.

$(29,30)$. The LICA seemed most resistant to interference in the samples; however, of the 11 samples with a "falsepositive" HBsAg result produced in either assay, 7 (63.64\%) were anti-HBc positive. We could not completely preclude the possibility of OBI $(30,31)$. If the ultrasensitive HBsAg assays are used $(7,21,24)$, trace amounts of HBsAg might be detected.

As a quantitative assay, the LICA showed much better within-run and within-laboratory precision than the Architect CLMIA assay. Theoretically, a large input sample volume is generally associated with increased precision. Nevertheless, the input volume of the LICA was much smaller than that of the Architect assay $(25 v s .75 \mu \mathrm{L})$. There might be two factors responsible for the increased precision. First, the LICA is based on a one-step homogeneous immunoreaction, and wash processes are not needed. This contributes to a more stable reaction system and a steady release of the test signal. Second, the sensitizer and emission microbeads used for the LICA were much smaller than those used for the Architect assay. They could be stably suspended in the reagent for a long time. Thus, the onboard reagent vortexing process to resuspend the beads was not needed, and the variation caused by the reagent was reduced accordingly. In contrast, the mechanistic performance of the immunoanalyzers also had a marked impact on the precision of the assays.

The hook effect is a major concern for one-step homogeneous immunoassays (32-34), including the Roche Elecsys HBsAg Quant II assay and the LICA. Excess HBsAg hinders the immunoassay by occupying the binding sites of the capture and detection antibodies simultaneously. As mentioned above, no samples with a high level of HBsAg were determined to be negative using the LICA. As a quantitative assay, however, it indeed underestimated $0.89 \%(46 / 5,176)$ of the total positive samples and $40.35 \%$ (46/114) of the samples with an HBsAg level greater than $10,000 \mathrm{IU} / \mathrm{mL}$ if the hook-free function was not used. The hook effect is detrimental to the accurate monitoring of 

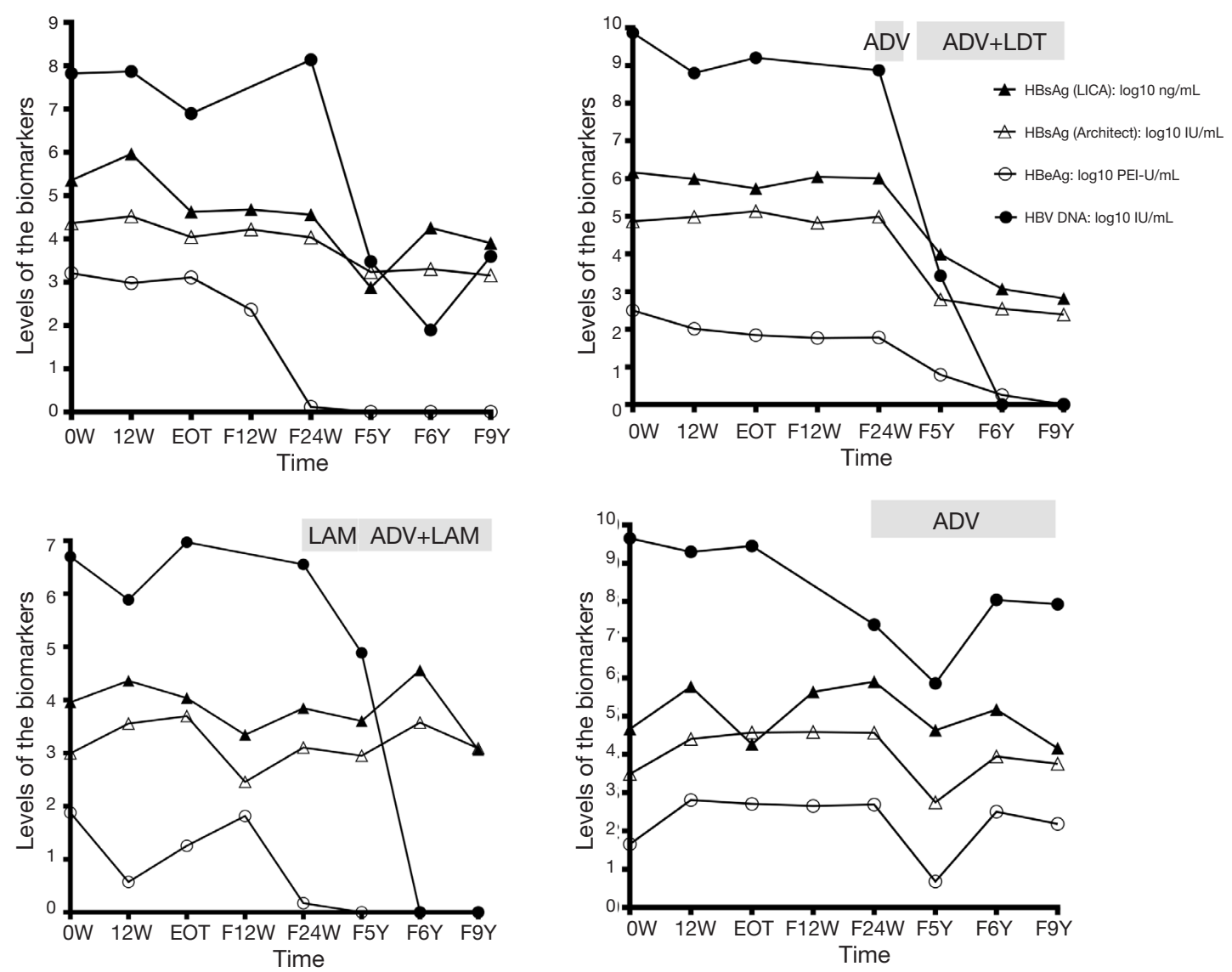

Figure 5 Dynamics of serum HBsAg, HBeAg, and HBV DNA in four patients treated with peginterferon for 24 weeks and followed up for 9 years. Three patients received NA treatment during the follow-up period. NAs and the treatment durations are indicated in gray at the top of each subfigure. HBsAg, hepatitis B surface antigen; HBeAg, hepatitis B e antigen; NA, nucleos(t)ide analogue; W, week; EOT, end of treatment with peginterferon; F12W, 12-week follow-up; F24W, 24-week follow-up; F5Y, 5-year follow-up; F6Y, 6-year follow-up; F9Y, 9-year follow-up; LAM, lamivudine; LDT, telbivudine; ADV, adefovir dipivoxil; ETV, entecavir.

HBV infectors and causes confusion among physicians and patients. Several hook-free technologies have recently been reported in immunochromatographic assays $(34,35)$. Here, we report a distinctive hook-free technology for the chemiluminescent assay for the first time; it was used in the state-of-the-art LICA. According to our results, the hook-free technology recognized $100 \%(46 / 46)$ of the hooked results. It should be noted that the cutoff value of the ratio $\left(\mathrm{RLU}_{15 \mathrm{~min}} /\right.$ $\mathrm{RLU}_{12 \mathrm{~min}}$ ) varied slightly for different lots of the reagents and calibrator. Nevertheless, a ratio $>2.0$ adequately ensured $100 \%$ sensitivity among four different lots during our study period. In addition, the application of the hook-free technology did not increase the cost greatly considering the limited number of potentially hooked samples.

As a hook-free quantitative assay, the LICA showed a strong correlation with the Architect assay. In addition, the HBsAg dynamics represented by the two assays also showed very similar patterns of fluctuation in CHB patients treated with interferon and/or NAs and followed up for a long period of time. We should mention that the unit of the Architect assay was traced to the WHO reference material, but that of the LICA was from the China national standard. The equation was prepared for the unit conversion, yet the WHO standard is suggested to be used to improve the traceability of the assay.

The performance of the LICA for measuring various genotypes and HBsAg mutations was also assessed. The sensitivity of many commercial assays might be subject to HBsAg mutations (36-38). However, our results showed that the LICA was resistant to these mutations. First, all 8 
HBsAg-positive samples missed by the assay had a low level of HBsAg ranging from 0.06 to $0.46 \mathrm{IU} / \mathrm{mL}$, approaching or even below the LOD of the assay. It was the low-level analyte but not the hook effect that was responsible for the reduced sensitivity of the LICA. Second, samples harboring HBsAg mutants were all detected by the LICA. Most of these mutations are commonly found in Asia and other areas around the world $(39,40)$. Third, the LICA gave quantitative results comparable to those of the Architect assay. Therefore, the underestimation of mutant HBsAg is unlikely. Moreover, we reported two uncommon multimutation patterns for the first time (Figure $4 B$ ). The LICA was also resistant to these combined mutations. The quality of the antibodies used in immunoassays plays a crucial role in the sensitivity and specificity. In the LICA, three types of antibodies were included. Two sets of mAbs were immobilized on the sensitizer beads, and a set of polyclonal antibodies were bound to the emission beads. The two mAbs recognized the configurative and linear epitopes, respectively, contributing to the high inclusivity of the mutants. Moreover, the HBsAg quantification was reported to be influenced by viral genotypes (23). Intriguingly, we fail to find such an influence (21). For most of the commercial assays, the target epitopes recognized by the capture and detection antibodies are confined to the conserved "a" determinant and adjacent regions, which harbor little difference in the amino acid sequence among genotypes. Therefore, the key mutations such as the G145R have greater impact on the binding affinity of the antibodies and the performance of commercial assays than the genotypes. This may partly explain why the quantitative HBsAg results in our studies are genotype independent.

Previous data have shown that LICA-like technology is suitable for detecting small molecules such as hormones and some new drugs, and for detecting antibodies against pathogens $(25,41-44)$. Our study shows that the LICA technology could also be extended to the measurement of much larger analytes, such as HBsAg, which is composed of various forms of particles with diameters ranging from 17 to $45 \mathrm{~nm}(8,45)$.

\section{Conclusions}

In conclusion, the new LICA provides a rapid approach for the large-scale screening of $\mathrm{HBV}$ infection. Furthermore, the novel hook-free algorithm is effective in diminishing the hook effect during the homogeneous immunoreaction process, making the LICA a promising approach for accurately quantifying serological biomarkers.

\section{Acknowledgments}

The authors thank Mrs. Baojuan Chen and Mr. Shiluan Yi for their writing assistance.

Funding: This work was supported by the Beijing Natural Science Foundation (No. 7173272, 7182174), the National Natural Science Foundation of China (NSFC) (No. 81870406), and the China National Science and Technology Major Project for Infectious Diseases Control during the 13th Five-Year Plan Period (No. 2017ZX10202202).

\section{Footnote}

Provenance and Peer Review: This article was commissioned by the Guest Editors (Zhi-De Hu, Bing Gu) for the series "Advances in laboratory tests for infectious diseases" published in Annals of Translational Medicine. The article was sent for external peer review organized by the Guest Editors and the editorial office.

Conflicts of Interest: All authors have completed the ICMJE uniform disclosure form (available at 10.21037/ atm.2020.02.59). The series "Advances in Laboratory Tests for Infectious Diseases" was commissioned by the editorial office without any funding or sponsorship. The authors have no other conflicts of interest to declare.

Ethical Statement: The authors are accountable for all aspects of the work in ensuring that questions related to the accuracy or integrity of any part of the work are appropriately investigated and resolved. Our study was approved by the Ethics Committees of Peking University People's Hospital and Peking University Third Hospital (No. 262-02). Informed consents from patients were waived due to the anonymity of individual patient data.

Open Access Statement: This is an Open Access article distributed in accordance with the Creative Commons Attribution-NonCommercial-NoDerivs 4.0 International License (CC BY-NC-ND 4.0), which permits the noncommercial replication and distribution of the article with the strict proviso that no changes or edits are made and the original work is properly cited (including links to both the formal publication through the relevant DOI and the license). See: https://creativecommons.org/licenses/by-nc$\mathrm{nd} / 4.0 /$. 


\section{References}

1. Locarnini S, Hatzakis A, Chen DS, et al. Strategies to control hepatitis B: Public policy, epidemiology, vaccine and drugs. J Hepatol 2015;62:S76-86.

2. Chen CJ, Wang LY, Yu MW. Epidemiology of hepatitis B virus infection in the Asia-Pacific region. J Gastroenterol Hepatol 2000;15 Suppl:E3-6.

3. Liang X, Bi S, Yang W, et al. Epidemiological serosurvey of hepatitis B in China--declining HBV prevalence due to hepatitis B vaccination. Vaccine 2009;27:6550-7.

4. Lu FM, Zhuang H. Management of hepatitis B in China. Chin Med J (Engl) 2009;122:3-4.

5. Fattovich G, Bortolotti F, Donato F. Natural history of chronic hepatitis B: special emphasis on disease progression and prognostic factors. J Hepatol 2008;48:335-52.

6. Song JE, Kim DY. Diagnosis of hepatitis B. Ann Transl Med 2016;4:338.

7. Shinkai N, Kusumoto S, Murakami S, et al. Novel monitoring of hepatitis $B$ reactivation based on ultrahigh sensitive hepatitis B surface antigen assay. Liver Int 2017;37:1138-47.

8. Brunetto MR. A new role for an old marker, HBsAg. J Hepatol 2010;52:475-7.

9. Mak LY, Seto WK, Fung J, et al. Use of HBsAg quantification in the natural history and treatment of chronic hepatitis B. Hepatol Int 2020;14:35-46.

10. Liu J, Yang HI, Lee MH, et al. Serum levels of hepatitis b surface antigen and dna can predict inactive carriers with low risk of disease progression. Hepatology 2016;64:381-9.

11. Ma H, Yang RF, Wei L. Quantitative serum HBsAg and $\mathrm{HBeAg}$ are strong predictors of sustained $\mathrm{HBeAg}$ seroconversion to pegylated interferon alfa- $2 \mathrm{~b}$ in HBeAg-positive patients. J Gastroenterol Hepatol 2010;25:1498-506.

12. Rijckborst V, Hansen BE, Ferenci P, et al. Validation of a stopping rule at week 12 using HBsAg and HBV DNA for $\mathrm{HBeAg}$-negative patients treated with peginterferon alfa2a. J Hepatol 2012;56:1006-11.

13. Martinot-Peignoux M, Asselah T, Marcellin P. HBsAg quantification to optimize treatment monitoring in chronic hepatitis B patients. Liver Int 2015;35 Suppl 1:82-90.

14. Liu J, Li T, Zhang L, et al. The role of hepatitis B surface antigen in nucleos(t)ide analogues cessation among asian patients with chronic hepatitis B: a systematic review. Hepatology 2019;70:1045-55.

15. Chien RN, Liaw YF. Re-treatment for severe hepatitis flare in $\mathrm{HBeAg}$-negative chronic hepatitis B: An appraisal with combined HBsAg/ALT kinetics. J Viral Hepat 2020;27:544-7.

16. Fanning GC, Zoulim F, Hou J, et al. Therapeutic strategies for hepatitis B virus infection: towards a cure. Nat Rev Drug Discov 2019;18:827-44.

17. Xia Y, Liang TJ. Development of direct-acting antiviral and host-targeting agents for treatment of hepatitis B virus infection. Gastroenterology 2019;156:311-24.

18. Cornberg M, Lok AS, Terrault NA, et al. Guidance for design and endpoints of clinical trials in chronic hepatitis B - Report from the 2019 EASL-AASLD HBV Treatment Endpoints Conference. Hepatology 2019. [Epub ahead of print].

19. Lee HJ, Kim SY, Lee SM, et al. Elecsys hepatitis B surface antigen quantitative assay: performance evaluation and correlation with hepatitis B virus DNA during 96 weeks of follow-up in chronic hepatitis B patients. Ann Lab Med 2012;32:420-5.

20. Xu W, Tong Y, Li Y. Comparison of Roche Elecsys and Sysmex HISCL immunoassays for the screening of common blood-borne pathogens. Ann Transl Med 2019;7:300.

21. Yang R, Song G, Guan W, et al. The Lumipulse G HBsAg-Quant assay for screening and quantification of the hepatitis B surface antigen. J Virol Methods 2016;228:39-47.

22. Zhang Z, Ding R, Lu W, et al. Performance evaluation of HBsAg by Lumipulse HBsAg-HQ: The agreement with HBsAg by Architect HBsAg-QT and the effectiveness in predicting liver tissue pathological states of chronic hepatitis B patients. Adv Clin Exp Med 2018;27:1045-54.

23. Murayama A, Momose H, Yamada N, et al. Evaluation of in vitro screening and diagnostic kits for hepatitis $\mathrm{B}$ virus infection. J Clin Virol 2019;117:37-42.

24. Lou S, Taylor R, Pearce S, et al. An ultra-sensitive Abbott ARCHITECT assay for the detection of hepatitis B virus surface antigen (HBsAg). J Clin Virol 2018;105:18-25.

25. Ullman EF, Kirakossian H, Singh S, et al. Luminescent oxygen channeling immunoassay: measurement of particle binding kinetics by chemiluminescence. Proc Natl Acad Sci U S A 1994;91:5426-30.

26. Yang R, Cong X, Xu Z, et al. INNO-LiPA HBV genotyping is highly consistent with direct sequencing and sensitive in detecting $\mathrm{B} / \mathrm{C}$ mixed genotype infection in Chinese chronic hepatitis B patients and asymptomatic HBV carriers. Clin Chim Acta 2010;411:1951-6.

27. Ma H, Yang RF, Li XH, et al. HBcrAg identifies patients failing to achieve $\mathrm{HBeAg}$ seroconversion treated with 
pegylated interferon Alfa-2b. Chin Med J (Engl)

2016;129:2212-9.

28. European Association for the Study of the Liver. EASL 2017 clinical practice guidelines on the management of hepatitis B virus infection. J Hepatol 2017;67:370-98.

29. Loomba R, Liang TJ. Hepatitis B reactivation associated with immune suppressive and biological modifier therapies: current concepts, management strategies, and future directions. Gastroenterology 2017;152:1297-309.

30. Bessone F, Dirchwolf M. Management of hepatitis $B$ reactivation in immunosuppressed patients: An update on current recommendations. World J Hepatol 2016;8:385-94.

31. Raimondo G, Locarnini S, Pollicino T, et al. Update of the statements on biology and clinical impact of occult hepatitis B virus infection. J Hepatol 2019;71:397-408.

32. Palomaki P. Simultaneous use of poly- and monoclonal antibodies as enzyme tracers in a one-step enzyme immunoassay for the detection of hepatitis B surface antigen. J Immunol Methods 1991;145:55-63.

33. Yang RF, Liu Y, Zhao CY, et al. A novel point-of-care oral anti-HCV assay: Is it reliable for screening hepatitis $\mathrm{C}$ virus infection in the era of direct-acting antivirals? PLoS One 2019;14:e0211795.

34. Oh J, Joung HA, Han HS, et al. A hook effect-free immunochromatographic assay (HEF-ICA) for measuring the C-reactive protein concentration in one drop of human serum. Theranostics 2018;8:3189-97.

35. Rey EG, O'Dell D, Mehta S, et al. Mitigating the hook effect in lateral flow sandwich immunoassays using realtime reaction kinetics. Anal Chem 2017;89:5095-100.

36. Alavian SM, Carman WF, Jazayeri SM. HBsAg variants: diagnostic-escape and diagnostic dilemma. J Clin Virol 2013;57:201-8.

37. Gencay M, Seffner A, Pabinger S, et al. Detection of in vivo hepatitis $B$ virus surface antigen mutations- $A$

Cite this article as: Yang R, Cui L, Liu Y, Cong X, Fei R, Wu S, Wei L. A hook-effect-free homogeneous light-initiated chemiluminescence assay: is it reliable for screening and the quantification of the hepatitis B surface antigen? Ann Transl Med 2020;8(9):606. doi: 10.21037/atm.2020.02.59 comparison of four routine screening assays. J Viral Hepat 2018;25:1132-8.

38. Xiang KH, Michailidis E, Ding H, et al. Effects of amino acid substitutions in hepatitis $\mathrm{B}$ virus surface protein on virion secretion, antigenicity, HBsAg and viral DNA. J Hepatol 2017;66:288-96.

39. Gencay M, Hubner K, Gohl P, et al. Ultra-deep sequencing reveals high prevalence and broad structural diversity of hepatitis B surface antigen mutations in a global population. PLoS One 2017;12:e0172101.

40. Kim HS, Chen X, Xu M, et al. Frequency of hepatitis B surface antigen variants (HBsAg) in hepatitis B virus genotype $\mathrm{B}$ and $\mathrm{C}$ infected East- and Southeast Asian patients: Detection by the Elecsys((R)) HBsAg II assay. J Clin Virol 2018;103:48-56.

41. Ullman EF, Kirakossian H, Switchenko AC, et al. Luminescent oxygen channeling assay (LOCI): sensitive, broadly applicable homogeneous immunoassay method. Clin Chem 1996;42:1518-26.

42. Yegorova S, Chavaroche AE, Rodriguez MC, et al. Development of an AlphaScreen assay for discovery of inhibitors of low-affinity glycan-lectin interactions. Anal Biochem 2013;439:123-31.

43. Cui Y, She T, Zhao H, et al. Competitive lightinitiated chemiluminescent assay: using 5-alphadihydrotestosterone-BSA as competitive antigen for quantitation of total testosterone in human sera. Anal Bioanal Chem 2019;411:745-54.

44. Yang S, Yang R, Zhang S, et al. Clinical diagnostic performance of light-initiated chemiluminescent assay compared with the Architect chemiluminescence immunoassay for detection of HCV antibody. J Clin Lab Anal 2019;33:e22928.

45. Lee JM, Ahn SH. Quantification of HBsAg: basic virology for clinical practice. World J Gastroenterol 2011;17:283-9. 